\title{
Research on the Influencing Factors and Promotion Measures of Knowledge Transfer in Industry-University-Research Alliance
}

\author{
Yimin Yin ${ }^{1, a^{*}}$ \\ ${ }^{1}$ School of Management, Wuhan University of Technology, Wuhan, China \\ a18211198588@163.com
}

Keywords: Industry-university-research cooperation; Industry-University-Research alliance; Knowledge transfer; Promotion measures

\begin{abstract}
With the development of economy, the innovation of enterprises can not meet the needs of enterprises. Knowledge transfer in industry-university-research alliance is the process of knowledge creation from universities and scientific research institutes, transfer to the enterprise and use the knowledge to create value. The establishment of industry-university-research alliance is conducive to the realization of knowledge transfer in universities and scientific research institutions to enterprises, expanding the knowledge stock of enterprises, and improving the ability of independent innovation. This paper summarizes the research results of domestic and foreign scholars, defines the connotation of industry-university-research alliance and alliance knowledge transfer, discussed the influence factors of alliance knowledge transfer, and makes research on knowledge transfer promotion measures. It can be used for reference to improve the knowledge transfer effect.
\end{abstract}

\section{The Connotation and Characteristics of Industry-University-Research Alliance}

Connotation of Industry-University-Research Alliance. Industry-university-research alliance is a product of the continuous development of industry university research cooperation. Compared with the traditional industry university research cooperation, the alliance has its unique meaning and characteristics, and also has higher requirements for the value relevance between the members. The establishment, implementation and promotion of the industry university research alliance play an important role in the development of national and social technological innovation activities and the improvement of comprehensive strength [1]. From the perspective of the components of the alliance, it includes three basic elements: Industry, University and research. General understanding of "Industry" refers to the enterprise; The University refers to the institutions of colleges and universities that can produce knowledge output; "Research" refers to the "Research Institute" [2]. The alliance is a senior form of cooperative development, mainly to enterprises, universities and research institutes as the main body, the intention of its own development strategy target and the government, and financial intermediaries and other related subjects based on the set up in order to adapt to the increasingly fierce market competition, seize new market opportunities, technological innovation, common vision, get the best benefits and the comprehensive advantages of a complementary, risk sharing, benefit sharing and common development cooperation [3]. From the perspective of innovation, alliance is a new organizational form of enterprise, national innovation system, in order to solve the problem is no longer a single short-term and temporary cooperation, but from a long-term point of view, in order to obtain sustainable competitive advantage, the formal organization to achieve long-term common development and the establishment of the. From an economic point of view, the industry university research alliance is an economic activity mode that the participants have the resources to optimize the allocation of two times to get the best benefits [4]. Industry-university-research alliance structure as shown in Fig.1. 


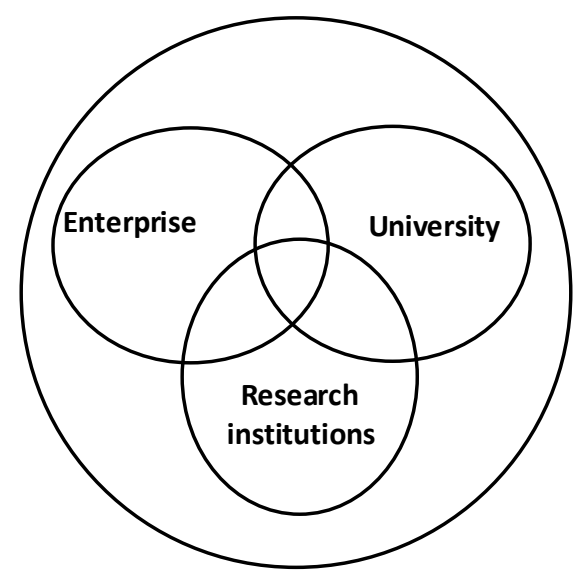

Figure 1. Structure of Industry-University-Research Alliance

Characteristics of Industry-University-Research Alliance. The alliance has the following characteristics: (1) Parties in the industry-university-research alliance is a cooperative relationship. However, as China's economy and the deepening of the reform of system of science and technology, a large number of research institutes or incorporated into the group, or incorporated into the University, or directly for the restructuring of science and technology enterprises, which leads to scientific research cooperation in the proportion gradually decreased. In the future cooperation, universities and enterprises will become the most core members, directly involved in technology development, product development and manufacturing activities and the actual government, financial institutions and intermediaries will become an important participant, for research activities to provide policy guidance, financial support and other related services. (2) The common goal of the alliance is to achieve win-win situation. The alliance parties intent in the alliance strategy is not the same, but the members of the alliance's goal is to rely on the alliance as a carrier, to make full use of the alliance to create value basis for the parties, to get more economic benefits, in this alliance has a high degree of consistency. It is this power of economic interest that brings together the parties and forms a common goal and vision. The alliance members duties, division of labor, sharing of results. However, the alliance members, the government generally does not undertake union specific tasks, but the use of the functions of government and policy influence and support of alliance development, such as science and technology to support the project, investment shares, or provide subsidies, subsidies and special capital support or thealliances products by the government procurement bidding part purchasing task. In the sharing of the results, the government to "industry university research cooperation fund" paid investment or lending, according to their contract or agreed to obtain the proceeds, to recover the investment. (3) The alliance can be a contractual relationship or a property right relationship. Specific tasks or a specific project based on alliance is a transitional form of organization, and is a member of alliance partnership signed a contract or agreement must be to regulate the conduct of the parties, when the goal or task and the completion of the project is to terminate the contract, the dissolution of alliance members of the technology, information and other intangible assets, equipment, workshop as the capital investment and research alliances, establish a relationship based on property rights. (4) Industry-university-research alliance is a complementary alliance. Due to resource and has the advantage in the alliance government, enterprises, schools, research institutes, financial institutions and other parties, play parties in the coalition role is different, the alliance has become a typical advantage of complementary Alliance[5].

\section{The Connotation of Knowledge Transfer in Industry University Research Alliance}

Foreign scholars have put forward the relevant interpretation of knowledge transfer. Ajay Agrawal proposed channels including publications, patents, consultation, informal meetings, employment, licensing, joint ventures, research contracts and personal exchange transfer to 
university industry knowledge, and different sources of different importance [6]. Spyros Arvanitis, Nora Sydow and Martin Woerter believes that from the perspective of R \& D strength and the sales of new products, the transfer of knowledge between research institutions and institutions of higher learning can improve the innovation performance of enterprises [7]. Scholars in China also give the relevant definitions. Yi Wang, Guisheng Wu proposed that through the cooperation of industry, University and research, it is an important way for enterprises to win the competitive advantage by transferring the external knowledge to the enterprise and creating value[8]. Xiang Wu, Hongtao Yang thinks that the knowledge transfer of industry university research cooperative innovation refers to the process of knowledge transfer from universities and research institutions to enterprises [9]. Deming Ceng, Yinfang He, Dun Peng for the production and research, knowledge transfer is the key to the use of knowledge and scientific research institutes and colleges and universities to create a virtuous circle of knowledge [10].

In general, knowledge is the key factor of alliance cooperation, and the core goal of alliance cooperation is to realize the effective transfer of knowledge. In the framework of cooperation alliance, knowledge transfer is not only the transfer of knowledge from one mind to another person's mind, but fundamentally realizes the knowledge elements from research party organization transfer applied to complex process of production organization. The research of knowledge transfer is a learning, creating, sharing and use of knowledge, the key lies in relying on the alliance sharing cooperation mechanism, will mainly come from the research results of knowledge transfer to production organization, promote the production technology enhance the strength and realize the value maximization of research and production.

\section{The Process and Influencing Factors of Knowledge Transfer in Industry-University -Research Alliance}

Process of knowledge transfer. Research technical alliance knowledge transfer in the knowledge alliance, is in the body of knowledge transfer and knowledge receiver transmission direction, absorbed by the process, which includes both the knowledge from the university to the enterprise, including knowledge from company to university. Alliance knowledge transfer, not only conducive to the activation of University Science and technology resources to create new precipitation, scientific and technological resources and commercial potential, help the commercialization, but also can improve the stock of knowledge enterprises, increase the opportunities for innovation. It depends on the transfer of knowledge in the alliance of industry, University and research, enhancing the interaction between universities and enterprises, and realizing the transformation of knowledge transfer from "one-way" to "two-way".

Knowledge transfer has a positive effect on the technological progress of enterprises and the promotion of scientific research ability. With technology as the representative of the knowledge transfer from the university basic research and applied research results for the enterprise products production technology, knowledge and the university is gradually separated and embedded into the parent organization and further interact. The basic research and applied research results in the university make the product through the test process, and make the commercial operation of the enterprise. Because the University sent out the knowledge does not necessarily apply directly to enterprises, so enterprises must be based on their own experience and needs to accept and trim from the University's knowledge, so that it can better meet the needs of enterprises, and internalization of enterprise knowledge system, finally solve the specific problems of enterprises. The process of knowledge transfer will not only help to increase the stock of knowledge enterprises, improve the level of enterprise technology, ease the pressure on resources, and through the introduction of advanced knowledge, University of digestion and absorption and "two innovation" helps to improve the enterprise's ability of independent research and development. After the completion of the knowledge transfer process, the enterprise then feedback the problem to the University, which provides the direction and the subject for further research.

The Influence Factors of Knowledge Transfer. According to the process of knowledge transfer in industry university research alliance, we can analyze the impact of the knowledge transfer of 
industry university research alliance has the following aspects, as shown in the fig. 2.

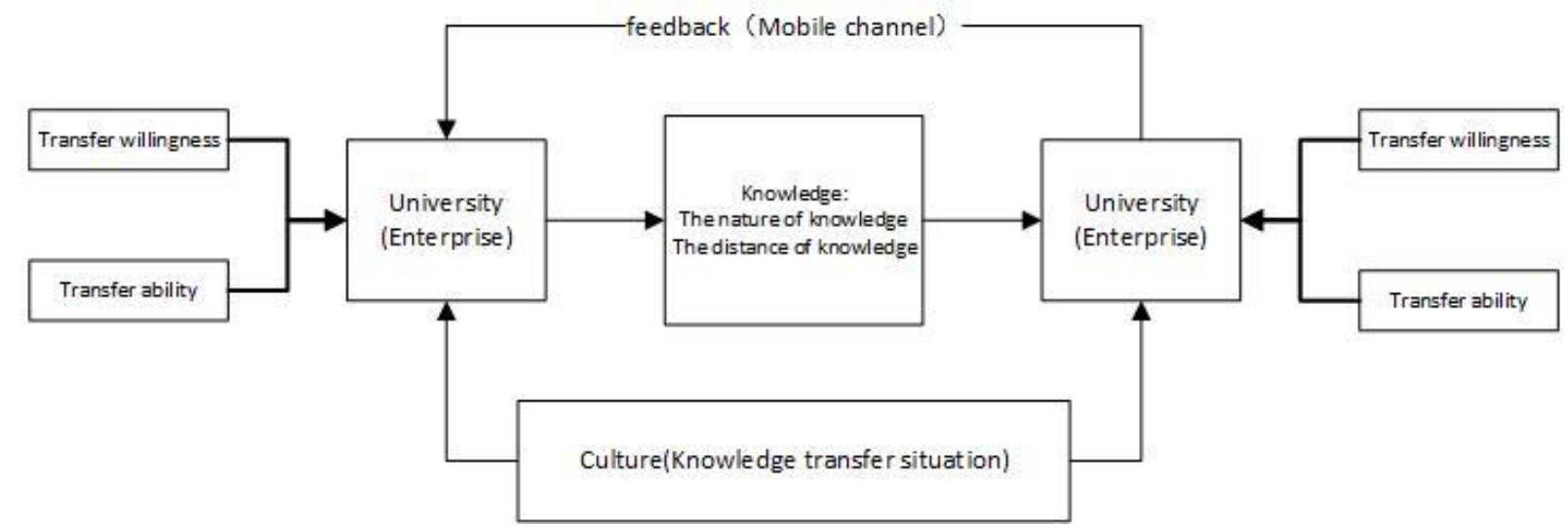

Figure 2. The influence factors of knowledge transfer

(1) Knowledge factors. The knowledge transfer of the strategic alliance of industry university research and technology innovation is an inter organizational system transfer, and its transfer scale and structure should be matched with the knowledge gap between knowledge supplier and knowledge recipient. At the same time, including not only the knowledge can be expressed with words, can be recorded in writing also includes explicit knowledge, tacit knowledge is hard to express in words, such as knowledge management, production skills, the knowledge transfer has certain difficulty in inter organization between.

(2) Transfer willingness and transfer ability of knowledge provider. The knowledge supply is usually the owner of knowledge, because knowledge of various kinds, in the University Alliance and enterprises is different from the owner of knowledge, knowledge can be the output intention and output capability is the two basic characteristics of the knowledge supply. Knowledge transfer can occur when the supplier's knowledge ability is higher than that of the recipient and the demand is completely or partly consistent with that of the recipient.

(3) Transfer willingness and transfer ability of knowledge recipient. The knowledge transfer in industry university research alliance is a two-way process. Learning willingness and absorptive capacity play an important role in the knowledge transfer of the alliance. Knowledge recipient's knowledge should be matched with its innovation ability.

(4) Cultural factors. Knowledge is the product of a certain situation, embedded in a particular situation, so the transfer of knowledge will inevitably be affected by the situation. From the perspective of culture, the focus of the research on knowledge transfer is the social cultural and institutional distance, cultural distance, the matching of knowledge and organizational culture. Therefore, in the process of knowledge transfer between universities and colleges and universities, because of the two different types of organizations, universities and enterprises will have a certain impact on knowledge transfer.

(5) Transfer channels factors. According to the information economics point of view, the full signal transmission is the premise of cooperation structure reached between different stakeholders, between University and enterprise information communication status only in the full range, to ensure that both sides of the ear is the best choice. Transfer channel is a means of transferring knowledge, its capacity, speed and fidelity directly determine the integrity of knowledge transfer.

\section{Promotion Measures of Knowledge Transfer In Industry-University -Research Alliance}

(1) Strengthen cultural cooperation. Strengthen cultural cooperation is not to eliminate the cultural differences between these two types of organizations, but to create a help to acquire and share knowledge, learning environment and cultural atmosphere, make with different cultural backgrounds between universities and enterprises to establish a rational spirit, respect each other's cultural differences. The cultural cooperation of the industry university research institute is to strengthen the communication and understanding of the two kinds of culture, mutual recognition and mutual integration. In the end, the alliance should form a new alliance culture, which is open to 
each other, mutual cooperation, knowledge sharing and organizational learning.

(2)Construction of two-way communication channels. Knowledge system is a dynamic and open process, which needs to absorb new knowledge and develop new ability. The role of communication is not only can improve the ability and level of the individual, the individual ability of filling up, but more importantly it can condense the whole alliance's ability to produce far more than the sum of the individual ability of force.

(3) Establishing trust mechanism of alliance members. First of all, the alliance should create a free and open environment, improve the frequency of contact between members of the alliance members, foster emotional trust between members, effectively promote knowledge transfer; Secondly, by holding regular technical training, seminars, professional skills training and visits and other activities to enhance their knowledge level and ability, improve the cognitive effect of trust and knowledge transfer; at the same time through the sound system, standardize the union parties behavior, thereby reducing the risk of knowledge transfer, knowledge transfer willingness to increase members.

(4) Constructing the learning exchange mechanism. One of the major factors affecting knowledge transfer success is the lack of organizational absorptive capacity, knowledge and related supplier knowledge gap, therefore, in order to enhance the absorption ability of the organization, the organization must strengthen learning, to promote the knowledge transfer in the process of alliance. From the perspective of organizational learning theory, successful knowledge transfer needs a well-designed learning system. The establishment of learning mechanism should be considered from two aspects: organization and individual. Individual learning is the micro foundation of the accumulation and activation of organizational ability, and organizational learning is an important reflection of the accumulation and activation of organizational capacity. The key factors of effective learning mechanisms in the alliance include: collaborative learning atmosphere, sharing knowledge, systematic thinking, knowledge conversion and creation, shared mental model and performance test, the relationship between learning and cooperative learning structure. The establishment of learning mechanism is helpful to improve the level of motivation of knowledge recipient, and to improve the knowledge absorptive capacity under the premise of establishing the knowledge base [11].

\section{Summary}

Knowledge transfer is a dynamic process, this is an important way of innovation and an effective means for enterprises to obtain and maintain competitiveness. Knowledge transfer in industry-university-research cooperation plays a key role in improving the innovation ability of enterprises. Universities and enterprises are different social entities, the knowledge transfer in industry-university-research cooperation can not only make the knowledge generated by universities and research institutes transferred to enterprises, but also promote the flow of talents between schools and enterprises. Knowledge transfer in industry-university-research alliance is affected by many factors, such as knowledge, knowledge supplier, knowledge recipient, culture, trust, and so on. In order to promote knowledge transfer, the alliance should continue efforts. First of all, the members of the industry-university-research alliance should build a cultural cooperate mechanism, and seeking common ground while reserving differences. Secondly, members should establish smooth communication channels to reduce the differences between members, so that more efficient cooperation. Thirdly, establish the alliance trust mechanism, strengthen the communication among the members, establish the system, improve the trust between members. Finally, establish the communication mechanism between the members, through learning to strengthen the organization's ability to absorb knowledge, thereby enhancing the effect of knowledge transfer, to achieve the maximization of the value of industry-University-research alliance. 


\section{References}

[1] Han Limin, Chen Ziqiang. The basic meaning and characteristics of the innovation alliance of production, teaching and research [J]. Journal of Ocean University of China (Social Science Edition), 2008 (6): 23-26.

[2] Lei Yong, Xu Fei. Study on the Research of Alliance of Production and Research [J] .Shanghai Management Science, 2007, 29 (5): 77-80.

[3] Atlan, Taylor. Bring Together Industry and University Engineering Schools in Getting More out for R\&D and Teehnology [J]. The conference Board, Research Report,1987(904).

[4] Masahiko A. Industry-University Cooperation to Take On Herefrom [J]. 2012.

[5] Lai Xinzheng. Study on model and operation of production and research technology innovation strategic alliance[D]. Central South University, 2008.

[6] Ajay Agrawal. University-to-Industry knowledge transfer: literature review and unanswered questions[J]. International Journal of Management Reviews, 2001,3(4):285-302.

[7] Spyros Arvanitis, Nora Sydow, Martin Woerter. Isthere any impact of university-industry knowledge transfer on innovation and productivity An empirical analysis based on Swiss firm data[J]. Review of Industrial Organization, 2008,32(2):77-94.114-121.

[8] Wang Yi, Wu Guisheng. Study on the causes and transfer mechanism of viscous knowledge in the cooperation of production and research [J] .Journal of Scientific Research Management, 2001,22 (6): 114-121.

[9] Wu Xiang, Yang Hongtao. Analysis on the influencing factors and the countermeasures of knowledge transfer in the cooperation of industry, academia and research[J]. Science and Technology Management Studies, 2009 (9): 360-362.

[10]Zeng Deming, He Yinfang, Peng Dun. Study on knowledge transfer obstacle in production and research system based on hypercycle theory [J]. Software Science, 2009, 32(7):1-11

[11]Lin Li, Zheng Xu, Ge Jiping. Study on influencing factors and promotion mechanism of knowledge transfer in production and research alliance $[\mathrm{J}]$. China Science and Technology Forum, 2009 (5): 39-43. 